\title{
Implementasi Sistem Rujukan Layanan Kesehatan: Systematic Literature Review
}

\author{
Sri Rahayu, Hosizah Hosizah \\ Program Studi Manajemen Informasi Kesehatan, Fakultas Ilmu-Ilmu Kesehatan, Universitas Esa Unggul, Jakarta, Indonesia \\ Jl. Arjuna Utara No. 9, Kebon Jeruk, Jakarta Barat, DKI Jakarta 11510 \\ Korespondensi E-mail: $\underline{\text { sri.ra1610@gmail.com }}$
}

Submitted: 8 Desember 2021, Revised: 29 Desember 2021, Accepted: 31 Desember 2021

\begin{abstract}
The Health Care Referral System is a service system that controls the delegation of authority and responsibility for health problems which is carried out reciprocally vertically or horizontally, in the sense of a unit with less capability to a more capable unit. The purpose of this study was to determine the implementation of the health service referral system in terms of regulations, health personnel resources and infrastructure. This research is a systematic review (Systematic Literature Review). The data synthesis process was carried out by comparing 15 literatures that met the quality assessment as well as inclusion and exclusion criteria with the database sources used, namely, Google Scholar, Pubmed, ScienceDirect. The data is processed and presented in tabulated form. The results showed that several countries such as Indonesia, Iran, Northern Tanzania, Riyadh, Ghana, Zambia and Hoduras from the articles reviewed used a referral system starting from the basic level (Primary), secondary level (Secondary) and tertiary level (Tertiary). Judging from the three aspects of the implementation of the health service referral system reviewed, it shows that there are problems in its implementation, including; the regulatory aspect found only 2 literatures that discussed regulations in the implementation of the referral system, the aspect of health personnel resources was found to be unavailability of health workers in health services causing patient referral and infrastructure aspects found obstacles in inadequate infrastructure resulting in referral.
\end{abstract}

Keywords: implementation, referral system, health care

\begin{abstract}
Abstrak
Sistem Rujukan Pelayanan Kesehatan merupakan sistem pelayanan yang mengendalikan pelimpahan wewenang serta tanggung jawab atas permasalahan kesehatan yang dilakukan secara timbal balik secara vertikal ataupun horizontal, dalam makna dari unit yang berkemampuan kurang ke unit yang lebih, terjangkau dan rasional. Tujuan penelitian ini untuk mengetahui implementasi sistem rujukan layanan kesehatan dilihat dari aspek regulasi, sumber daya tenaga kesehatan dan sarana prasarana. Penelitian ini merupakan tinjauan sistematis (Systematic Literature Review). Proses data sintesis dalam penelitian ini dilakukan dengan cara membandingkan 15 literature yang memenuhi penilaian kualitas serta kriteria inklusi dan ekslusi dengan sumber database yang digunakan yaitu, Google Scholar, Pubmed, ScienceDirect. Data diolah dan disajikan dalam bentuk tabulasi. Hasil penelitian menunjukan beberapa negara seperti Indonesia, Iran, Tanzania Utara, Riyadh, Ghana, Zambia dan Hoduras dari artikel yang direview menggunakan sistem rujukan yang dimulai dari tingkat dasar (Primary), tingkat menengah (Secondary) dan tingkat tersier (Tertiary). Dilihat dari ketiga aspek implementasi sistem rujukan layanan kesehatan yang direview menunjukkan adanya permasalahan dalam pengimplementasiannya diantaranya; aspek regulasi ditemukan hanya 2 literature yang membahas regulasi dalam pengimplementasian sistem rujukan, aspek sumber daya tenaga kesehatan ditemukannya ketidaktersediaan tenaga kesehatan di layanan kesehatan sehingga menyebabkan terjadinya rujukan pasien dan aspek sarana prasarana ditemukannya hambatan pada infrastruktur yang tidak memadai sehingga menyebabkan terjadinya rujukan
\end{abstract}

Kata Kunci: implementasi, sistem rujukan, layanan kesehatan

\section{Pendahuluan}

Keadaan sehat didefinisikan oleh organisasi kesehatan dunia/World Health Organization (WHO) sebagai keadaan sejahtera dari aspek fisik, mental, sosial dan tidak hanya terbebasnya seseorang dari penyakit ataupun kecacatan. Adapun pembangunan kesehatan dimana diarahkan agar dapat meningkatkan kesadaran, kamauan dan kemampuan hidup yang sehat setiap manusia supaya dapat terwujudnya derajat yang setinggi-tingginya (1). 
Berdasarkan Peraturan Menteri Kesehatan Republik Indonesia Nomor 001 Tahun 2012 tentang Sistem Rujukan Pelayanan Kesehatan Perorangan merupakan sistem pelayanan yang mengendalikan pelimpahan wewenang serta tanggung jawab atas permasalahan kesehatan yang dilakukan secara timbal balik secara vertikal ataupun horizontal, dalam makna dari unit yang berkemampuan kurang ke unit yang lebih, terjangkau, rasional dan tidak dibatasi oleh wilayah administrasi (2). Menurut Tolulope O Afolaranmi, et.al. (2018) menerangkan bahwa rujukan ialah pelimpahan aktivitas yang dilakukan penyedia layanan kesehatan disebabkan ketidakmampuannya untuk memberikan intervensi diagnostik serta terapeutik lebih lanjut yang berkaitan dengan kebutuhan keperawatan kesehatan pasien (3).

Sistem rujukan yang efektif dan efisien dapat menyediakan layanan kesehatan yang terintegrasi dan saling berkesinambungan untuk melakukan perawatan (4). Metode yang digunakan agar mencapai sistem rujukan yang efektif dan efisien yaitu metode komunikasi efektif. Komunikasi efektif atau dua arah yang baik akan berpengaruh terhadap pertukaran informasi yang dilakukan oleh profesi kesehatan dari layanan kesehatan yang merujuk ke layanan tingkat lanjut (5). Implementasi suatu sistem tidak berjalan dengan baik bila penerapannya tidak sesuai dengan syarat kebijakan yang berlaku. Salah satu permasalahan dalam implementasi sistem rujukan ialah keterbatasan sumber daya serta infrastruktur yang esensial dalam institusi kesehatan (6).

Tegawende Pierre Ilboudo, et.al menjelaskan, sistem rujukan yang berlangsung dengan efisien dan efektif sangatlah penting untuk pemberian perawatan kesehatan tingkat lanjut, akan tetapi seringkali sistem rujukan di daerah Pedesaan Niger menunjukan sedikit adanya halangan dan keterlambatan untuk sampai ke rumah sakit tingkat lanjut (7). Hal-hal seperti ini disebabkan adanya kekurangan dari komponen sistem rujukan itu sendiri. Komponen yang dimaksud yaitu, kurangnya pengetahuan masyarakat mengenai sistem rujukan, sarana prasarana, tenaga kesehatan yang kurang memadai, adanya berbagai sistem komunikasi, sistem informasi manajemen, administrasi dan sistem organisasi.

Dalam penelitiannya Sartini Risky dan Ari Nofitasari menemukan bahwa angka rujukan di fasilitas kesehatan tingkat pertama di Sulawesi Tenggara masih tinggi dengan pencapaian 17\% pada tahun 2016 dimana idealnya untuk angka rujukan maksimal di fasilitas tingkat pertama tidak lebih dari $5 \%$. Penyebab terjadinya peningkatan rujukan di fasilitas tersebut terdiri dari beberapa aspek yaitu, aspek dari sumber daya manusia (adanya ketidakprofesionalan dari bidan, tidak terjalinnya komunikasi yang efektif antar petugas, minimnya jumlah dokter yang bertugas serta kurangnya pemahaman tenaga kesehatan mengenai sistem rujukan), ketersediaan fasilitas yang masih kurang dan minimnya persediaan obat-obatan (8).

Sistem rujukan pada layanan kesehatan di Indonesia masih terdapat adanya permasalahanpermasalahan dalam pelaksanaannya diantaranya kurangnya kepercayaan serta keyakinan pasien terhadap layanan kesehatan rujukan, biaya pengobatan, tindakan medis yang dilakukan oleh tenaga kesehatan di rumah sakit rujukan, minimnya tenaga kesehatan (9). Tenaga kesehatan yang akan melakukan rujukan dilihat apabila layanan kesehatannya kurang memadai dimana dipengaruhi oleh beberapa aspek terdiri dari, kebutuhan untuk konsultasi dibidang spesialis, akses mengarah keperlengkapan kedokteran yang lebih mutahir dengan harapan kesuksesan pengobatan yang lebih baik, waktu ataupun transportasi serta jarak tempuh (10).

Berdasarkan penjelasan diatas, peneliti tertarik untuk melakukan penelitian dengan Systematic Review mengenai implementasi sistem rujukan layanan kesehatan. Adapun salah satu bentuk tindak lanjutnya adalah dengan mempelajari lebih lanjut perihal implementasi sistem rujukan dari aspek regulasi sistem rujukan layanan kesehatan, implementasi sistem rujukan dari aspek sumber daya tenaga kesehatan dalam sistem rujukan layanan kesehatan dan implementasi sistem rujukan dari aspek sarana prasarana fasilitas layanan kesehatan dalam sistem rujukan layanan kesehatan.

\section{Metode Penelitian}

1. Strategi Pencarian Data (Search Strategy)

Jenis penelitian ini adalah tinjauan sistematis (Systematic Literature Review), yakni metodologi penelitian atau riset tertentu dan pengembangan yang dilakukan untuk mengumpulkan serta mengevaluasi suatu penelitian yang terkait pada fokus topik tertentu (11). Adapun rincian 
kegiatannya terdiri dari menentukan strategi pencarian data dan/atau sumber informasi, seleksi studi melalui penilaian kualitas sesuai dengan kriteria eligibilitas serta instrumen penilaian kualitas, data sintesis dan data ekstraksi.

Kata kunci dan boolean operator yang digunakan dalam pencarian literature yakni "inbibition" OR "implementation" OR "regulation" AND "referral system" OR "referral system healthcare" OR "referral" OR "bealthcare".

2. Sumber Informasi (Information Sources)

Sumber database yang digunakan dalam mencari literature dalam penelitian ini yaitu, Google Scholar, Pubmed, ScienceDirect.

3. Kriteria Eligibilitas (Eligibility Criteria)

Kriteria eligibilitas dalam penelitian ini meliputi kriteria inklusi dan eksklusi. Kriteria inklusi dalam penelitian ini adalah 1) Literature berbentuk jurnal ilmiah dan/atau prosiding, 2) Sumber jurnal ilmiah dan/atau prosiding PubMed, Google Scholar, ScienceDirect, 3) Jurnal ilmiah dan/atau prosiding memiliki akses terbuka, 4) Artikel harus dapat diakses full text, 5) Jurnal ilmiah dan/atau prosiding menggunakan bahasa Inggris atau bahasa Indonesia, 6) Tahun publikasi jurnal ilmiah dan/atau prosiding antara 2013-2020, 7) Pembahasan dalam jurnal ilmiah dan prosiding meliputi implementasi sistem rujukan layanan kesehatan dilihat dalam regulasi sistem rujukan atau aspek sumber daya tenaga kesehatan atau aspek sarana prasarana layanan kesehatan, 8) Desain penelitiannya deskriptif atau kualitatif. Sedangkan kriteria eksklusi dalam penelitian ini adalah bentuk denotasi dari kriteria inklusi. Selain itu agar membatasi ruang lingkup penelitian, peneliti menggunakan metode PICO (Population/Problem, Intervention, Comparison, Outcomes), seperti Tabel berikut:

Tabel 1

Ringkasan PICO

\begin{tabular}{ll}
\hline \multicolumn{1}{c}{ Komponen } & \multicolumn{2}{c}{ Keterangan } \\
\hline Population/Problem & Sistem Rujukan \\
Intervention & Deskripsi implementasi Sistem Rujukan Layanan Kesehatan \\
Comparison & $\mathrm{n} / \mathrm{a}$ \\
Outcomes & Implementasi Sistem Rujukan Layanan Kesehatan meliputi \\
& $\begin{array}{l}\text { aspek regulasi sisem rujukan layanan kesehatan, aspek } \\
\text { sumber daya tenaga kesehatan, aspek sarana prasarana } \\
\text { layanan kesehatan }\end{array}$ \\
\hline
\end{tabular}

4. Penilaian Kualitas

Seleksi literaturee menggunakan metode PRISMA (Preferred Reporting Items for Systematic Reviens and Meta-analyses). PRISMA Flow Diagram dalam penelitian ini ditampilkan dalam Gambar 1. 


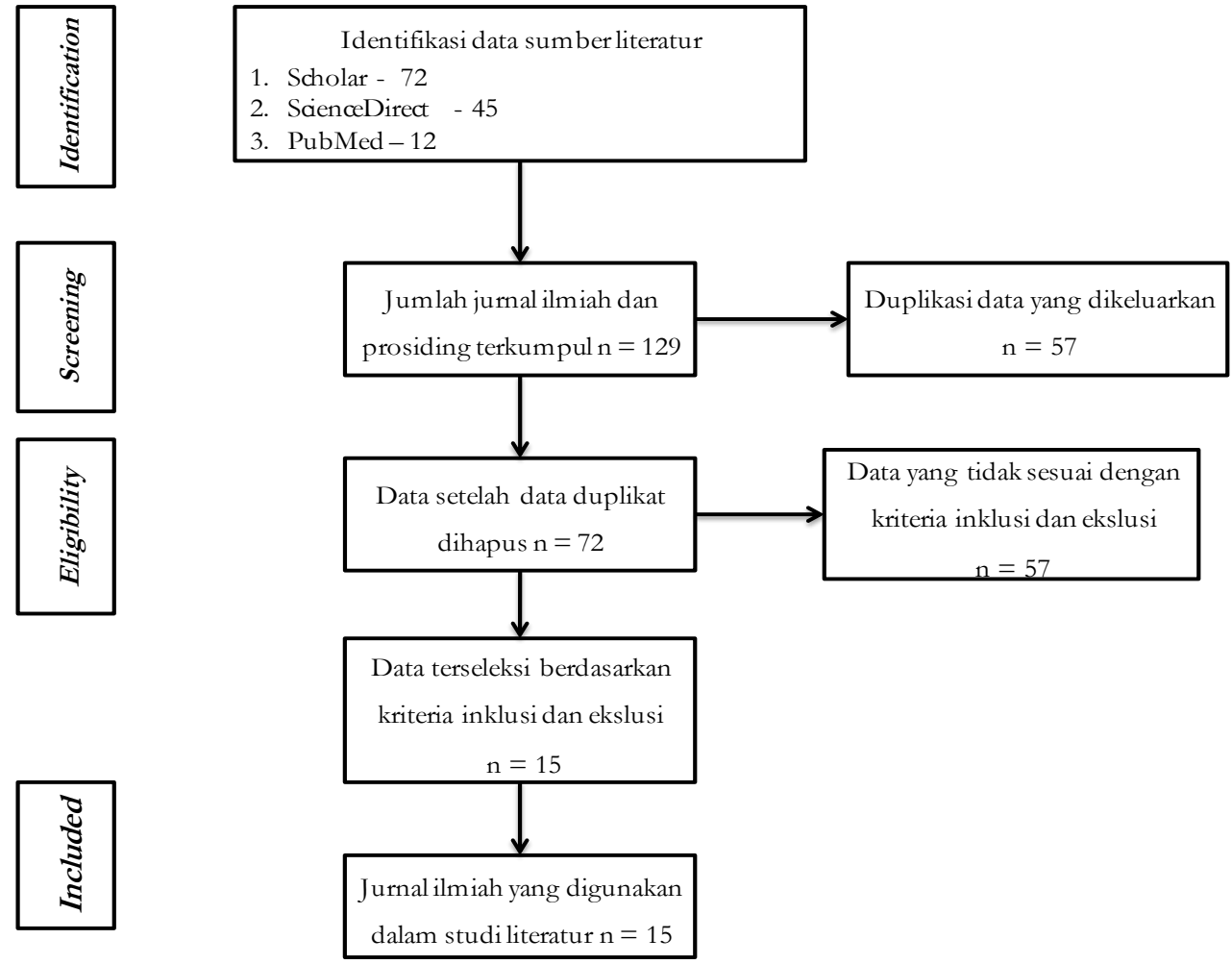

Gambar 1

PRISMA Flow Diagram

Berdasarkan metode PRISMA yang telah dilakukan, dapat diperoleh hasil yakni dari total 129 jurnal artikel dan prosiding yang diidentifikasi, 57 diantaranya dikeluarkan karena terjadi duplikasi data, selanjutnya 57 lainnya tidak memenuhi kriteria inklusi dan eksklusi. Sehingga hanya 15 jurnal artikel yang digunakan dalam studi literature.

Penilaian kualitas artikel dalam penelitian ini menggunakan Standards for Reporting Qualitative Research (SRQR) - Checklist. SRQR - Checklist berisi 21 komponen penilaian kualitas. Adapun jumlah jurnal ilmiah dan/atau prosiding yang menggunakan instrumen tersebut adalah 15. Jurnal ilmiah dan/atau prosiding harus memenuhi komponen penilaian kualitas minimal 15 agar dapat digunakan sebagai sumber literature dalam penelitian ini. Berdasarkan penilaian kualitas yang telah dilakukan, 15 (lima belas) jurnal dan/atau prosiding memenuhi pencapaian minimal tersebut, sehingga dapat digunakan sebagai sumber literature dalam penelitian ini.

5. Data Sintesis

Proses data sintesis dalam penelitian ini dilakukan dengan cara membandingkan literature yang telah memenuhi penilaian kualitas serta kriteria inklusi dan eksklusi. Data sintesis mengacu pada tujuan penelitian yakni mengetahui implementasi sistem rujukan layanan kesehatan mencakup aspek regulasi yang berlaku, aspek sumber daya tenaga kesehatan, aspek sarana prasarana layanan kesehatan

6. Ekstraksi Data

Adapun output ekstraksi data adalah berupa Tabel yang terdiri dari nama peneliti, tahun publikasi, judul penelitian, objek penelitian, desain penelitian, tempat penelitian, dan manfaat penerapan sistem rujukan layanan kesehatan (regulasi yang berlaku, aspek sumber daya tenaga kesehatan, aspek sarana prasarana layanan kesehatan yang memadai). 


\section{Hasil dan Pembahasan}

Hasil penelitian kualitas literature dan ekstraksi data yang telah dilakukan, diketahui dari 15 literature yang terdiri dari 8 literature dengan tempat penelitiannya di Indonesia dan 7 literature dengan tempat penelitiannya di Luar Indonesia. Negara yang menjadi tempat penelitian yang digunakan dalam literature ini adalah Iran, Tanzania Utara, Riyadh (Saudi Arabia), Zambia, Ghana dan Honduras. Literature yang paling banyak dibahas dalam implementasi sistem rujukan dari tiga aspek yang diteliti adalah aspek sumber daya tenaga kesehatan dengan total literature $15(100 \%)$, sedangkan untuk aspek sarana prasana layanan kesehatan yang memadai menduduki kedua terbanyak yang dibahas dengan jumlah $8(53 \%)$ dan untuk aspek regulasi yang digunakan menduduki ketiga terbanyak dengan jumlah 2 $(13 \%)$.

\section{Gambaran Umum Sistem Rujukan Layanan Kesehatan Di Berbagai Negara}

Sistem rujukan merupakan suatu sistem pelayanan kesehatan yang mengatur mengenai pelimpahan wewenang, tanggung jawab tenaga kesehatan di suatu pelayanan kesehatan dikarenakan sumber daya yang tidak mencukupi (seperti obat-obatan, peralatan medis dan keterampilan dari tenaga kesehatannya) untuk mengelola suatu kasus yang dilakukan secara timbal balik atau mengambil alih pengelolaan secara penuh (12). Sistem rujukan diartikan dengan terjadinya sebuah rujukan pasien dari layanan kesehatan tingkat pertama atau dari layanan kesehatan yang tidak memadai ke layanan kesehatan tingkat lanjut atau dari layanan yang memadai dalam hal ini layanan kesehatan tingkat nasional atau layanan kesehatan khusus. Setiap negara mempunyai sistem rujukannya masing-masing, dalam hal ini literature yang digunakan tempat penelitiannya berasal dari 8 (delapan) negara yang berbeda yaitu; Indonesia, Iran, Tanzania Utara, Riyadh (Saudi Arabia), Zambia, Ghana dan Honduras.

1) Sistem Rujukan Di Negara Indonesia

Berdasarkan dengan Peraturan Presiden Indonesia mengenai Jaminan Kesehatan maka layanan kesehatan yang ada di Indonesia menerapkan sistem rujukan dimulai dari fasilitas kesehatan dasar atau tingkat perata atau fasilitas kesehatan primer yang mempunyai peran sebagai gate keeper dan apabila masyarakat memerlukan pengobatan tingkat lanjut maka akan di rujuk ke fasilitas kesehatan tingkat lanjut terdekat sesuai dengan sistem rujukan yang diatur dalam ketentuan peraturan perundang-undangan. Sistem rujukan dikecualikan bagi peserta yang berada di luar wilayah fasilitas kesehatan tingkat pertama atau dalam keadaan kegawatdaruratan medis. Dalam hal ini untuk mengatur berjalanannya sistem rujukan yang sesuai dengan prosedur yang ada maka pemerintah menyusun suatu pedoman sistem rujukan nasional yang dimana isi dari pedoman tersebut menjelaskan bagaimana langkah-langkah dalam membangun sistem rujukan dan penjelasan mengenai rujukan yang dapat difungsikan secara berkesinambungan yang dimulai dari pelayanan kesehatan perseorangan tingkat pertama sampai pada tingkat rujukan tertinggi (13). Tabel 2 menjelaskan klasifikasi fasilitas pelayanan kesehatan dalam implementasi sistem rujukan yang ada di Indonesia. 
Tabel 2

Klasifikasi Fasilitas Pelayanan Kesehatan Dalam Implementasi Sistem Rujkan Di Indonesia Jenjang Rujukan $\quad$ Pengertian $\quad$ Fasilitas Pelayanan Kesehatan Mampu memberikan pelayanan 1.Klinik Puskesmas (di Puskesmas kesehatan perseorangan/medik tingkat Perawatan atau Puskesmas Rawat Inap pertama dilaksanakan oleh dan Puskesmas Non Perawatan)

Fasyankes Tingkat Pertama dokter/dokter gigi dan khusus untuk

2.Klinik Pratama (milik Pemerintah dan layanan maternal dan neonatal Swasta) phisiologis dan kondisi tertentu 3.Praktek perseorangan dokter/dokter gigi ditolong oleh bidan 4.Rumah Sakit Pratama

1.Rumah Sakit Kelas D atau Kelas C

Fasyankes Tingkat Dua Mampu memberikan layanan

2.Rumah Sakit Kelas B Non Pendidikan kesehatan perseorangan spesialistik (Milik Pemerintah ABRI/Polri/BUMN, Swasta

1.Rumah Sakit Kelas B atau A Pendidikan di Provinsi

Fasyankes Tingkat Tiga

Mampu memberikan layanan kesehatan perseorangan sub spesialistik

2.Rumah Sakit A Rujukan Utama Umum/Khusus Nasional di Pusat

2) Sistem Rujukan Di Negara Iran

(Sumber: Pedoman Rujukan Nasional Tahun 2012)

Sistem perawatan kesehatan primer Iran ditempatkan di daerah pedesaan dan perkotaan untuk meningkatkan perawatan kesehatan bagi orang-orang yang kurang beruntung dan untuk mengurangi kesenjangan antara hasil kesehatan. Ini dimulai dari pusat perawatan primer di daerah tersebut dan berlanjut ke tingkat sekunder dan tersier di pusat yang lebih tinggi. 10 (sepuluh) sistem rujukan di semua lingkungan perawatan kesehatan primer (PHC) memastikan kemungkinan akses yang adil ke perawatan kesehatan sekunder dan tersier oleh semua anggota masyarakat (14).

3) Sistem Rujukan Di Negara Tanzania Utara

Tanzania Utara memiliki sistem rujukan kesehatan secara hierarki dalam hal ini dimana sistem pemerintahannya dilakukan secara terdesentralisasi dan diatur dalam piramida rujukan, terdiri dari tiga tingkat utama, yaitu; Tingkat Dasar atau Primary, Tingkat Menengah atau Secondary dan Tingkat Tersier atau Tertiary (15). Tingkatan dasar atau primer pelayanan kesehatan dimulai dari dispensaries (penyedia layanan kesehatan skala kecil atau yang disebut dengan apotik yang menawarkan pertolongan pertama dalam sistem kesehatan di negara-negara afrika), pusat kesehatan (puskesmas) dan rumah sakit distrik atau kabupaten menjadi pusat rujukan pertama untuk semua fasilitas kesehatan, tingkatan menengah atau secondary terdapat rumah sakit rujukan regional yang menjadi rumah sakit rujukan apabila dari tingkatan dasar tidak dapat memberikan pelayanan kesehatan secara memadai dan untuk tingkatan tersier atau tertiary merupakan tingkatan rujukan yang paling tinggi dimana fasilitas kesehatan yang tersedia adalah rumah sakit tingkat nasional atau rumah sakit khusus.

4) Sistem Rujukan Di Negara Riyadh (Saudi Arabia)

Sistem rujukan di Arab Saudi memainkan peran utama dalam mengelola alur perawatan pasien dari perawatan primer ke sekunder dan tersier (karena struktur sistem perawatan kesehatan didasarkan pada tiga tingkat perawatan tersebut). Profesional medis melaporkan terdapat dua jenis rujukan yaitu rujukan elektif dan rujukan darurat. Rujukan elektif itu sendiri diartikan sebuah rujukan rutin (terencana) dimana kondisi pasien akan dievaluasi terlebih dahulu di fasiltas perawatan primer dan kemudian akan dirujuk ke fasilitas perawatan sekunder bahkan perawatan tersier dengan kondisi pasien tertentu yang sesuai dengan jangka waktu yang dapat dijadwalkan oleh kedua belah pihak. Sedangkan untuk rujukan darurat merupakan pasien dengan kasus tertentu dan dapat melakukan perawatan langsung menuju fasilitas perawatan sekunder dengan keadaan tertentu dapat dirujuk langsung ke perawatan tersier (16).

5) Sistem Rujukan Di Negara Zambia

Sistem rujukan di Zambia adalah dari masyarakat ke pos kesehatan lalu ke pusat kesehatan atau puskesmas dan selanjutnya ke rumah sakit kabupaten, umum, dan pusat. Sistem ini bergantung pada kemampuan pasien untuk mengenali komplikasi dan mencari perawatan, dan selanjutnya 
kemampuan petugas kesehatan untuk mengenali dan mengambil tindakan tepat waktu pada setiap komplikasi yang mungkin timbul (17).

6) Sistem Rujukan Di Negara Ghana

Kementrian Kesehatan berkomitmen untuk menyediakan layanan kesehatan berkualitas bagi seluruh masyarakat. Dimana semua penyedia layanan kesehatan yang ada di Ghana harus melakukan rujukan pasien dengan tepat untuk memastikan penyediaan berkelanjutan. Sistem rujukan ini mempunyai tiga tingkatan perawatan yaitu primer, sekunder dan tersier (18). Sistem rujukan mengharuskan pasien mengakses terlebih dahulu perawatan primer dan dirujuk ke tingkat yang sesuai dengan kondisi pasien apabila diperlukannya rujukan tersebut. Akan tetapi, pasien sering kali mengabaikan perawatan tingkat pertama dikarenakan ketidaktahuan pasien mengenai sistem rujukan yang berlaku, fasilitas sarana prasarana perawatan tingkat pertama yang tidak memadai dan kurangnya kepercayaan terhadap layanan yang diberikan fasilitas tingkat pertama. Sedangkan untuk rumah sakit tersier adalah titik rujukan terakhir dimana perawatan diberikan oleh spesialis untuk kasus yang kompleks.

7) Sistem Rujukan Di Negara Honduras

Perawatan kesehatan Honduras didesentralisasi dimana peran serta daerah terutama kabupaten atau distrik atau kota yang menjadi peran penting dalam upaya memfungsikan sistem rujukan yang dibangun sesuai dengan ketentuannya. Penyediaan layanan kesehatan yang ada di Honduras terbagi menjadi; 1) CESAR (Centro de Salud Rural: pusat kesehatan pedesaan, setara dengan pos kesehatan) di mana hanya perawat pembantu yang memberikan layanan; 2) CESAMO (Centro de Salud con Me"dico: pusat kesehatan dengan dokter), menyediakan layanan rawat jalan dan laboratorium; 3) Area Rumah Sakit (kurang lebih 50 tempat tidur dengan penyakit dalam, bedah, obstetri dan ginekologi, dan pediatri); 4) Rumah Sakit Daerah (sekitar 100 sampai 150 tempat tidur dengan empat layanan dasar yang disebutkan di atas dan beberapa bangsal khusus); 5) Rumah Sakit Nasional (rumah sakit rujukan yang sangat khusus yang terdiri dari tiga rumah sakit umum, dua rumah sakit jiwa dan satu rumah sakit dada) (19).

Implementasi Sistem Rujukan dari Aspek Regulasi Sistem Rujukan Layanan Kesehatan

Hasil dari systematic literature review yang dilakukan, peneliti menganalisa dari 15 (lima belas) literature yang digunakan dalam penelitian ini untuk implementasi sistem rujukan dari aspek regulasi sistem rujukan layanan kesehatan, diperoleh data dari hasil analisa dimana hanya 2 (dua) literature yang membahas mengenai aspek regulasi sistem rujukan layanan kesehatan dan tempat penelitian ini berasal dari negara Indonesia. Berikut dibawah ini merupakan Tabel hasil dari review yang telah dilakukan:

Tabel 3

Implementasi Sistem Rujukan Berdasarkan Aspek Regulasi Sistem Rujukan Layanan Kesehatan

\begin{tabular}{|c|c|c|c|}
\hline Judul & Penulis & Tempat Penelitian & $\begin{array}{c}\text { Aspek Regulasi Sistem Rujukan } \\
\text { Layanan Kesehatan }\end{array}$ \\
\hline $\begin{array}{l}\text { Analisis Sistem } \\
\text { Rujukan Jaminan } \\
\text { Kesehatan } \\
\text { Nasional RSUD. } \\
\text { Dr. Adjidarmo } \\
\text { Kabupaten Lebak }\end{array}$ & $\begin{array}{l}\text { Karleanne Lony } \\
\text { Primasari }\end{array}$ & $\begin{array}{l}\text { RSUD Dr. Adjidarmo, } \\
\text { Kabupaten Lebak, } \\
\text { Indonesia }\end{array}$ & $\begin{array}{l}\text { Adanya kebijakan direktur mengenai } \\
\text { Pedoman Sistem Rujukan yang } \\
\text { mengacu pada PMK No. 001, Tahun } \\
2012 \text { yang berlaku. Pelaksanaan } \\
\text { kebijakan tersebut belum dijalankan } \\
\text { oleh seluruh tenaga kesehatan, karena } \\
\text { terbatasnva sosialisasi. }\end{array}$ \\
\hline $\begin{array}{l}\text { Regionalization } \\
\text { Referral System of } \\
\text { the Hospital } \\
\text { National Health } \\
\text { Insurance }\end{array}$ & $\begin{array}{l}\text { Amir Mahmud Hafsa, } \\
\text { Alimin Maidin, Sukri } \\
\text { Palutturi, Stang }\end{array}$ & $\begin{array}{l}\text { RS Daya sebagai } \\
\text { rujukan tingkat kedua, } \\
\text { RS Wahidin sebagai RS } \\
\text { tersier atau rujukan } \\
\text { tingkat terakhir dan } \\
\text { Dinas Kesehatan } \\
\text { Sulawesi Selatan }\end{array}$ & $\begin{array}{l}\text { Regionalisasi sistem rujukan } \\
\text { merupakan salah satu bentuk } \\
\text { pengelolaan rujukan kesehatan di } \\
\text { rumah sakit provinsi/kabupaten/kota } \\
\text { yang tidak terlepas dari sistem } \\
\text { pelayanan kesehatan di Provinsi } \\
\text { Sulawesi Selatan dan sistem ini } \\
\text { menjadi program unggulan } \\
\text { penyelenggaraan pemerintahan } \\
\text { Sulawesi Selatan yang dilaksanakan } \\
\text { dalam memberikan rujukan yang } \\
\text { berkualitas. }\end{array}$ \\
\hline
\end{tabular}


Berdasarkan Tabel 3 yang membahas implementasi sistem rujukan berdasarkan aspek regulasi yang berlaku pada layanan kesehatan menjelaskan bahwa sistem rujukan yang berlaku di RSUD Dr. Adjidarmo Kabupaten Lebak mengacu pada PMK No. 001 tahun 2012 dimana pelaksanaan kebijakan ini masih belum sepenuhnya dilaksanakan oleh tenaga kesehatan dengan baik dikarenakan adanya keterbatasan sosialisasi dan regulasi sistem rujukan layanan kesehatan yang berlaku di Provinsi Sulawesi Selatan bahwa pemerintah daerah menerapkan sistem regionalisasi rujukan dimana regulasi ini menjadi program unggulan dari penyelenggaraan pemerintahan dalam rangka memberikan harapan rujukan yang berkualitas (20)(21).

\section{Implementai Sistem Rujukan dari Aspek Sumber Daya Tenaga Kesehatan dalam Sistem Rujukan} Layanan Kesehatan

Peneliti menganalisa dari 15 literature yang digunakan dalam penelitian ini untuk implementasi sistem rujukan dari aspek sumber daya tenaga kesehatan dalam sistem rujukan layanan kesehatan. Dimana dari 15 literature yang terdiri dari 8 literature dengan tempat penelitiannya di Indonesia dan 7 literature dengan tempat penelitiannya di Luar Indonesia yaitu; Iran, Tanzania Utara, Riyadh (Saudi Arabia), Zambia, Ghana dan Honduras. Berikut dibawah ini merupakan Tabel hasil review yang telah dilakukan.

Tabel 4

Implementasi Sistem Rujukan dari Aspek Sumber Daya Tenaga Kesehatan Di Negara Indonesia Judul Penulis $\quad$ Tempat $\quad$ Aspek Sumber Daya Kesehatan Penelitian

\begin{tabular}{|c|c|c|c|}
\hline $\begin{array}{l}\text { Pelaksanaan Sistem Rujukan } \\
\text { di RSUD Banyudono }\end{array}$ & $\begin{array}{l}\text { Puspitaningtyas } \\
\text { A, Indarwati, } \\
\text { Kartikasari D }\end{array}$ & $\begin{array}{l}\text { RSUD } \\
\text { Banyudono, Kec. } \\
\text { Banyudono, } \\
\text { Kabupaten } \\
\text { Boyolali, Jawa } \\
\text { Tengah, Indonesia }\end{array}$ & $\begin{array}{l}\text { Terdapat } 59 \text { tenaga kesehatan yang } \\
\text { diwawancarai dimana sebanyak } 31 \\
(52,5 \%) \text { responden melakukan rujukan } \\
\text { sesuai prosedur sistem rujukan, } 40 \\
(67,8 \%) \text { responden melakukan rujukan } \\
\text { sesuai mekanisme sistem rujukan, } 34 \\
(57,6 \%) \text { responden melakukan } \\
\text { persiapan rujukan sesuai dengan } \\
\text { pelaksanaan sistem rujukan }\end{array}$ \\
\hline $\begin{array}{l}\text { Implementasi Rujukan } \\
\text { Pasien Jaminan Kesehatan } \\
\text { Nasional (JKN) Badan } \\
\text { Penyelenggara Jaminan } \\
\text { Sosial (BPJS) Di Puskesmas } \\
\text { Singgani Kecamatan Palu } \\
\text { Timur Kota Palu }\end{array}$ & $\begin{array}{l}\text { Hermiyanty, } \\
\text { Bertin Ayu } \\
\text { Wandira, Fitri } \\
\text { Nelianti }\end{array}$ & $\begin{array}{l}\text { Puskesmas } \\
\text { Singgani Kec. Palu } \\
\text { Timur, Kota Palu, } \\
\text { Indonesia }\end{array}$ & $\begin{array}{l}\text { Variabel sumber daya manusia yaitu } \\
\text { dokter sudah memadai yang berjumlah } \\
4 \text { orang dokter umum dan } 1 \text { orang } \\
\text { dokter gigi }\end{array}$ \\
\hline $\begin{array}{l}\text { Analisis Sistem Rujukan } \\
\text { Jaminan Kesehatan Nasional } \\
\text { RSUD. Dr. Adjidarmo } \\
\text { Kabupaten Lebak }\end{array}$ & $\begin{array}{l}\text { Karleanne } \\
\text { Lony Primasari }\end{array}$ & $\begin{array}{l}\text { RSUD Dr. } \\
\text { Adjidarmo, } \\
\text { Kabupaten Lebak, } \\
\text { Indonesia }\end{array}$ & $\begin{array}{l}\text { Sumber daya tenaga kesehatan yang } \\
\text { masih kurang rasa disiplin dalam } \\
\text { bekerja dan kurangnya rasa } \\
\text { bertanggung jawab dari tenaga } \\
\text { kesehatan }\end{array}$ \\
\hline $\begin{array}{l}\text { Evaluasi Pelaksanaan Sistem } \\
\text { Rujukan Di Puskesmas } \\
\text { Bogor Utara Kota Bogor } \\
\text { Provinsi Jawa Barat Tahun } \\
2019\end{array}$ & $\begin{array}{l}\text { Dian Nur } \\
\text { Afiyani, Eny } \\
\text { Dwimawati, } \\
\text { Suci Pujiati }\end{array}$ & $\begin{array}{l}\text { Puskesmas Bogor } \\
\text { Utara, Kota Bogor, } \\
\text { Indonesia }\end{array}$ & $\begin{array}{l}\text { Jumlah dari tenaga kesehatan di } \\
\text { Puskesmas kurang dari standar } \\
\text { peraturan Permenkes No. } 75 \text { tahun } \\
2014 \text { dimana menjelaskan jumlah } \\
\text { tenaga kesehatan harus terdiri dari } 31 \\
\text { orang, sementara sumber daya } \\
\text { manusia di Puskesmas Bogor Utara } \\
\text { hanya terdapat } 28 \text { tenaga kesehatan }\end{array}$ \\
\hline
\end{tabular}

Proses Sistem Rujukan dalam Pelayanan Kegawatdaruratan Obstetri dan Neonatal di Puskesmas Sayung 2 Kabupaten Demak
Dinda

Nestelita, Puskesmas Sayung

Suryoputro, 2, Kabupaten Wulan

Demak, Indonesia

Adanya double job tenaga kesehatan serta kurangnya tenaga kesehatan yang terlatih PONED 


\begin{tabular}{|c|c|c|c|}
\hline Judul & Penulis & $\begin{array}{c}\text { Tempat } \\
\text { Penelitian }\end{array}$ & Aspek Sumber Daya Kesehatan \\
\hline $\begin{array}{l}\text { Implementasi Sistem } \\
\text { Rujukan Di Rumah Sakit } \\
\text { Bhayangkara Kota Kendari } \\
\text { Tahun } 2018\end{array}$ & $\begin{array}{l}\text { Fany Putri } \\
\text { Ayuandira, } \\
\text { Ambo Sakka, } \\
\text { Jumakil }\end{array}$ & $\begin{array}{l}\text { RS Bhayangkara, } \\
\text { Kota Kendari, } \\
\text { Indonesia }\end{array}$ & $\begin{array}{l}\text { 1. Petugas Kesehatan di RS } \\
\text { Bhayangkara masih menemukan } \\
\text { adanya ketidaksesuaian diagnosa } \\
\text { pasien pada saat administrasi sehingga } \\
\text { petugas tersebut membuat keputusan } \\
\text { akan mengikuti tujuan poli pasien; } 2 \text {. } \\
\text { Kepatuhan petugas terhadap SOP } \\
\text { rujakan masih ditemukannya } \\
\text { ketidakpatuhan; } 3 \text {. Petugas RS } \\
\text { Bhayangkara terkadang mendahulukan } \\
\text { pelayanan dibandingkan pemenuhan } \\
\text { syarat administrasi }\end{array}$ \\
\hline
\end{tabular}

Evaluation of the

Implementation of a

Referral System in the

Community Health Center Sartini Risky,

of Abeli, Kendari, Indonesia Ari Nofitasari

RSUD Abeli, Kota

Kendari, Indonesia

1. Sumber daya tenaga medis yang masih kurang memadai; 2. Kurang adanya rasa tanggung jawab dari bidan.

\begin{tabular}{|c|c|c|c|}
\hline $\begin{array}{l}\text { Regionalization Referral } \\
\text { System of the Hospital } \\
\text { National Health Insurance }\end{array}$ & $\begin{array}{l}\text { Amir Mahmud } \\
\text { Hafsa, Alimin } \\
\text { Maidin, Sukri } \\
\text { Palutturi, Stang }\end{array}$ & $\begin{array}{l}\text { RS Daya sebagai } \\
\text { rujukan tingkat } \\
\text { kedua, RS Wahidin } \\
\text { sebagai RS tersier } \\
\text { atau rujukan } \\
\text { tingkat terakhir } \\
\text { dan Dinas } \\
\text { Kesehatan } \\
\text { Sulawesi Selatan }\end{array}$ & $\begin{array}{l}\text { 1. Adanya masyarakat yang tidak } \\
\text { mengetahui mengenai bagaimana } \\
\text { peraturan mengenai regionalisasi } \\
\text { sistem rujukan; } 2 \text {. Adanya bias } \\
\text { informasi kepada kebijakan dan } \\
\text { penyelenggara, kegagalan pendidikan } \\
\text { oleh kebijakan dan penyelenggara yang } \\
\text { menyebabkan masyarakat atau } \\
\text { penerima tidak mematuhi regionalisasi } \\
\text { rujukan. }\end{array}$ \\
\hline
\end{tabular}

Dalam penelitiannya Puspitaningtyas A, et al (2014) mengungkapkan bahwa sumber daya tenaga kesehatan di RSUD Banyudono sebanyak 59 (lima puluh sembilan) tenaga kesehatan sudah melakukan prosedur rujukan tanpa adanya kendala dalam melakukan rujukan (9). Peneliti lainnya yaitu Hermiyanty, et al (2019) menyatakan variabel sumber daya tenaga kesehatan khususnya dokter untuk Puskesmas Singgani Kecamatan Palu Timur sudah memadai sehingga aspek sumber daya tenaga kesehatan tidak menjadi faktor utama untuk melakukan rujukan (22). Dilihat dari 6 (enam) literature dari 8 (delapan) literature yang lain menjelaskan masih terdapatnya kekurangan sumber daya tenaga kesehatan yang terdapat di Indonesia baik dari personal tenaga kesehatan ataupun perilaku ketidakprofesional dari tenaga kesehatan itu sendiri, adanya bias informasi anatara pembuat kebijakan rujukan dengan penyelenggara rujukan dan masih kurangnya informasi mengenai sistem rujukan dikalangan masyarakat (20)(23)(24)(25)(8)(21). 
Tabel 5

Implementasi Sistem Rujukan dari Aspek Sumber Daya Tenaga Kesehatan Di Negara Iran, Tanzania Utara, Riyadh (Saudi Arabia), Zambia, Ghana dan Honduras

Judul Penulis Tempat Penelitian

Referral system in rural Iran: improvement proposals
Naseriasl M, Janati A, Amini A, Adham D
Kementerian Kesehatan dan Pendidikan Medis Iran (MoHME). Kementerian Kesehatan dan Pendidikan Medis Iran (MoHME).

Aspek Sumber Daya Tenaga Kesehatan

1. Adanya reformasi pendidikan kedokteran dimana didalamnya harus mencakup konsep, persyaratan, dan isu-isu yang berkaitan dengan proses rujukan dan bahwa diperlukan lebih banyak pelatihan dan pedoman klinis daripada buku teks; 2. Adanya pelatihan tenaga kesehatan agar dapat meningkatkan pengetahuan

1.Jumlah tenaga kesehatan yang terbatas serta jumlah kehadirannya di layanan kesehatan yang terbatas; 2 . Masih adanya staf tenaga kesahatan yang belum sepenuhnya memahami dan mengetahui sistem rujukan dalam proses pelayanan kesehatan

Rumah Kesehatan dan Rumah Peserta Di Negara Iran
Abbas Abbaszadeh, Rural Societies in Iran
Fariba Borhani
Surgical Referrals In

Northern Tanzania:

A Prospective

Assessment Of

Rates,

Preventability,

Reasons And

Patterns
Desmond T. Jumbam

, Gopal Menon,

Tenzing N. Lama,

William Lodge, Sarah

Maongezi, Ntuli A.

Kapologwe
Sampel 20 fasilitas kesehatan di 5 wilayah di Zona Danau dipilih, Tanzania Utara, Afrika Timur
Kurangnya kebutuhan tenaga spesialis dengan spesialis yang paling dibutuhkan yang dilaporkan adalah ahli bedah ortopedi (21\%), ahli urologi $(12,5 \%)$ dan ahli bedah saraf $(7 \%)$

1. Penelitian menunjukkan bahwa 29 dokter perawatan primer $(67,44 \%)$ setuju bahwa kesadaran dari dokter umum yang buruk mengenai klinik perawatan sekunder; 2. Sejumlah 25 dokter $(58,2 \%)$ setuju bahwa

Management Of Inappropriate Referrals In Wazarat Health Center, Riyadh, Saudi Arabia
Saad Mohammad Albattal
Wazarat Health Center (WHC), Riyadh, Saudi Arabia pengetahuan dokter umum yang kurang mengenai rujukan dapat berkontribusi dalam memutuskan rujukan yang tidak tepat; 3 . Hasil dari 43 dokter yang disurvei 36 dokter $(83,8 \%)$ setuju bahwa permintaan dan tuntutan pasien untuk dirujuk merupakan faktor utama yan menyebabkan pasien melakukan rujukan yang tidak tepat di WHC

Assessment Of

Maternal Referral

Systems Used For A

Rural Zambian

Hospital: The

Development Of

Setting Specific

Protocols For The

Identification Of

Complications
Ashley E Benson, Michael J Benson, Amy H Luke
Rumah Sakit Misi Lumezi, Zambia
Terbatasnya sumber daya manusia terampil yang mengakibatkannya tidak berjalannya perawatan kesehatan tingkat lanjut secara merata dikarenakan pemerintah hanya mampu mempekerjakan 40\% dari dokter yang dibutuhkan di Zambisa, akibatnya di pedesaan Zambia hanya $31 \%$ perangkat yang dibantu oleh petugas kesehatan ang terampil 


\begin{tabular}{|c|c|c|c|}
\hline Judul & Penulis & Tempat Penelitian & $\begin{array}{c}\text { Aspek Sumber Daya Tenaga } \\
\text { Kesehatan }\end{array}$ \\
\hline $\begin{array}{l}\text { Improving } \\
\text { Emergency } \\
\text { Obstetric Referral } \\
\text { Systems In Low } \\
\text { And Middle Income } \\
\text { Countries: A } \\
\text { Qualitative Study In } \\
\text { A Tertiary Health } \\
\text { Facility In Ghana }\end{array}$ & $\begin{array}{l}\text { Anita Anima Daniels } \\
\text { and Aaron Abuosi }\end{array}$ & $\begin{array}{l}\text { Rumah Sakit Pendidikan } \\
\text { Korle Bu, Ghana }\end{array}$ & $\begin{array}{l}\text { Pada saat melakukan rujukan pasien } \\
\text { seringkali tidak didampingi oleh } \\
\text { tenaga kesehatan dikarenakan rumah } \\
\text { sakit dan klinik rujukan kekurangan } \\
\text { staf }\end{array}$ \\
\hline $\begin{array}{l}\text { Obstetric Referrals } \\
\text { From A Rural Clinic } \\
\text { To A Community } \\
\text { Hospital In } \\
\text { Honduras }\end{array}$ & $\begin{array}{l}\text { Srirama Josyula, BS } \\
\text { (Medical Student), } \\
\text { Kathryn K. Taylor, BS } \\
\text { (Medical Student), } \\
\text { Blair M. Murphy, MD } \\
\text { (Radiation Medicine } \\
\text { Resident) }\end{array}$ & $\begin{array}{l}\text { Maternal Fetal Care } \\
\text { Clinic, Honduras, } \\
\text { Amerika Tengah }\end{array}$ & $\begin{array}{l}\text { Adanya penundaan dari tenaga } \\
\text { kesehatan dalam memutuskan untuk } \\
\text { mencari layanan kesehatan rujukan }\end{array}$ \\
\hline
\end{tabular}

Dari hasil dari literature review yang tertera dalam Tabel 5 menerangkan bahwa sumber daya tenaga kesehatan menjadi salah satu alasannya dilakukannya rujukan pasien ke fasilitas kesehatan lebih lanjut. Dalam penelitiannya Manijeh Eskandari, et al (2013) mengungkapkan jumlah tenaga kesehatan yang terbatas di layanan kesehatan pedesaan Iran yang menyebabkan pasien menunggu antrian untuk mendapatkan pengobatan dan kurangnya pengetahuan dari tenaga kesehatan yang belum sepenuhnya memahami sistem rujukan dalam proses pelayanan kesehatan (14). Selain itu, peneliti Ashley E Benson, et al (2019) menerangkan masih adanya keterbatasan sumber daya tenaga kesehatan yang terampil di Zambia yang mengakibatkannya tidak berjalannya perawatan kesehatan tingkat lanjut secara merata sehingga mengakibatkan terjadinya rujukan pasien ke pelayanan kesehatan lebih lanjut (17). Penelitian lainnya mengungkapkan bahwa tenaga kesehatan masih harus mendapatkan pelatihan mengenai sistem rujukan, harus ada peningkatan pengetahuan mengenai sistem rujukan (4)(26)(16)(27)(28).

\section{Implementai Sistem Rujukan dari Aspek Sarana Prasarana Fasilitas Layananan Kesehatan dalam Sistem Rujukan Layanan Kesehatan}

Berdasarkan hasil systematic literature review yang dilakukan, peneliti menganalisa dari 15 (lima belas) literature yang digunakan dalam penelitian ini untuk implementasi sistem rujukan dari aspek sarana prasarana fasilitas layanan kesehatan dalam sistem rujukan layanan kesehatan diperoleh data yaitu, dimana hanya 8 (delapan) literature yang digunakan membahas mengenai aspek sarana prasarana fasilitas layanan kesehatan dalam sistem rujukan layanan kesehatan. Tempat penelitian yang ditemukan dalam literature yaitu; Indonesia, Tanzania Utara, Zambian, Ghana dan Honduras. Berikut dibawah ini merupakan Tabel hasil review yang telah dilakukan. 
Tabel 6

Implementasi Sistem Rujukan Berdasarkan Aspek Sarana Prasarana Layanan Kesehatan Di Indonesia

\begin{tabular}{|c|c|c|c|}
\hline Judul & Penulis & Tempat Penelitian & $\begin{array}{c}\text { Aspek Sarana Prasarana Layanan } \\
\text { Kesehatan }\end{array}$ \\
\hline $\begin{array}{l}\text { Implementasi } \\
\text { Rujukan Pasien } \\
\text { Jaminan Kesehatan } \\
\text { Nasional (JKN) } \\
\text { Badan } \\
\text { Penyelenggara } \\
\text { Jaminan Sosial } \\
\text { (BPJS) Di } \\
\text { Puskesmas Singgani } \\
\text { Kecamatan Palu } \\
\text { Timur Kota Palu }\end{array}$ & $\begin{array}{l}\text { Hermiyanty, Bertin } \\
\text { Ayu Wandira, Fitri } \\
\text { Nelianti }\end{array}$ & $\begin{array}{l}\text { Puskesmas Singgani } \\
\text { Kec. Palu Timur, Kota } \\
\text { Palu, Indonesia }\end{array}$ & $\begin{array}{l}\text { Sarana prasarana yang ada kurang } \\
\text { untuk menunjang pelayanan } \\
\text { kesehatan dimana ditemukannya } \\
\text { beberapa alat kesehatan yang tidak } \\
\text { tersedia di Puskesmas seperti } \\
\text { stetoskop kebidanan (fetoskop), palu } \\
\text { refleks, otoskop, forcep hemostatik } \\
\text { RO viewer, OSHA (Approved } \\
\text { Resuscitation Mouthpieces), lampu } \\
\text { spiritus, loupe (kaca pembesar). }\end{array}$ \\
\hline $\begin{array}{l}\text { Analisis Sistem } \\
\text { Rujukan Jaminan } \\
\text { Kesehatan Nasional } \\
\text { RSUD. Dr. } \\
\text { Adjidarmo } \\
\text { Kabupaten Lebak }\end{array}$ & $\begin{array}{l}\text { Karleanne Lony } \\
\text { Primasari }\end{array}$ & $\begin{array}{l}\text { RSUD Dr. Adjidarmo, } \\
\text { Kabupaten Lebak, } \\
\text { Indonesia }\end{array}$ & $\begin{array}{l}\text { Masih kurangnya peran pemerintah } \\
\text { daerah dalam memfasilitasi } \\
\text { kelayakan akses menuju RSUD Dr. } \\
\text { Adjidarmo }\end{array}$ \\
\hline $\begin{array}{l}\text { Evaluasi } \\
\text { Pelaksanaan Sistem } \\
\text { Rujukan Di } \\
\text { Puskesmas Bogor } \\
\text { Utara Kota Bogor } \\
\text { Provinsi Jawa Barat } \\
\text { Tahun } 2019\end{array}$ & $\begin{array}{l}\text { Dian Nur Afiyani, } \\
\text { Eny Dwimawati, Suci } \\
\text { Pujiati }\end{array}$ & $\begin{array}{l}\text { Puskesmas Bogor Utara, } \\
\text { Kota Bogor, Indonesia }\end{array}$ & $\begin{array}{l}\text { Sarana dan Prasarana yang ada di } \\
\text { Puskesmas Bogor Utara sudah } \\
\text { memadai dengan adanya sarana dan } \\
\text { prasarana komputer yang sudah } \\
\text { menggunakan sistem primary care dan } \\
\text { Sistem Informasi Rumah Sakit } \\
\text { (SIRS) dan sudah dilengkapi dengan } \\
\text { jaringan internet yang memadai }\end{array}$ \\
\hline $\begin{array}{l}\text { Evaluation of the } \\
\text { Implementation of a } \\
\text { Referral System in } \\
\text { the Community } \\
\text { Health Center of } \\
\text { Abeli, Kendari, } \\
\text { Indonesia }\end{array}$ & $\begin{array}{l}\text { Sartini Risky, Ari } \\
\text { Nofitasari }\end{array}$ & $\begin{array}{l}\text { RSUD Abeli, Kota } \\
\text { Kendari, Indonesia }\end{array}$ & $\begin{array}{l}\text { Adanya ketidaklengkapan peralatan } \\
\text { medis terutama alat yang digunakan } \\
\text { untuk membantu pemeriksaan bidan } \\
\text { dan dokter }\end{array}$ \\
\hline
\end{tabular}

Berdasarkan hasil Tabel 6 yang membahas implementasi sistem rujukan berdasarkan aspek sarana prasarana layanan kesehatan menurut Dian Nur Afiyani, et al (2020) untuk sarana prasarana di layanan kesehatannya sudah memadai dimana sudah memiliki akses ke primary care dan Sistem Informasi Rumah Sakit (SIRS) (23). Berdasarkan hasil yang dikemukakan oleh Karleanne Lony Primasari (2015) bahwa kurangnya peran pemerintah daerah dalam memfasilitasi kelayakan akses menuju RSUD Dr. Adjidarmo (20). Sedangkan penelitian lainnya menjelaskan bahwa adanya kekurangan dalam pelaksanaan sistem rujukan berdasarkan aspek sarana prasarana yaitu, ketidaktersediaan alat medis yang memadai (22)(8).

Tabel 7 menerangkan bahwa terdapat 6 literature yang ditemukan oleh peneliti bahwa sarana prasarana di layanan kesehatan masih adanya kekurangan sehingga menyebabkan terjadinya rujukan ke layanan kesehatan dengan sarana prasarana yang memadai. Kekurangnya sarana prasarana ini bisa dilihat dari adanya hambatan infrastruktur dan trasportasi yang tidak memadai dari layanan kesehatan yang berada di daerah pedesaan ke rumah sakit rujukan, ketidaktersediaan alat medis yang memadai, tempat tidur pasien yang tidak memadai dan ketidaktersediaann jaringan seluler atau jaringan radio sehingga mengakibatkan terhambatnya proses rujukan pasien (26)(17)(27)(28). 
Tabel 7

Implementasi Sistem Rujukan Berdasarkan Aspek Sarana Prasarana Layanan Kesehatan Di Negara Tanzania Utara, Zambia, Ghana dan Honduras

\begin{tabular}{|c|c|c|c|}
\hline Judul & Penulis & Tempat Penilitian & $\begin{array}{c}\text { Aspek Sarana Prasaran Layanan } \\
\text { Kesehatan }\end{array}$ \\
\hline $\begin{array}{l}\text { Surgical Referrals In } \\
\text { Northern Tanzania: } \\
\text { A Prospective } \\
\text { Assessment Of } \\
\text { Rates, } \\
\text { Preventability, } \\
\text { Reasons And } \\
\text { Patterns }\end{array}$ & $\begin{array}{l}\text { Desmond T. Jumbam } \\
\text {, Gopal Menon, } \\
\text { Tenzing N. Lama, } \\
\text { William Lodge, Sarah } \\
\text { Maongezi, Ntuli A. } \\
\text { Kapologwe }\end{array}$ & $\begin{array}{l}\text { Sampel } 20 \text { fasilitas } \\
\text { kesehatan di } 5 \text { wilayah } \\
\text { di Zona Danau dipilih, } \\
\text { Tanzania Utara, Afrika } \\
\text { Timur }\end{array}$ & $\begin{array}{l}\text { Kurangnya peralatan diagnostik } \\
\text { pencitraan atau rontgen }(26,1 \%) \text {, } \\
\text { kurangnya suplai medis dan bahan } \\
\text { habis pakai }(15,7 \%) \text { dan kurangnya } \\
\text { peralatan diagnostik laboratorium } \\
(13,4 \%) \text {. }\end{array}$ \\
\hline $\begin{array}{l}\text { Assessment Of } \\
\text { Maternal Referral } \\
\text { Systems Used For A } \\
\text { Rural Zambian } \\
\text { Hospital: The } \\
\text { Development Of } \\
\text { Setting Specific } \\
\text { Protocols For The } \\
\text { Identification Of } \\
\text { Complications }\end{array}$ & $\begin{array}{l}\text { Ashley E Benson, } \\
\text { Michael J Benson, } \\
\text { Amy H Luke }\end{array}$ & $\begin{array}{l}\text { Rumah Sakit Misi } \\
\text { Lumezi, Zambia }\end{array}$ & $\begin{array}{l}\text { Terdapat gangguan jaringan seluler } \\
\text { dan penggunaan radio yang tidak } \\
\text { konsisten menyebabkannya } \\
\text { terhambatnya proses rujukan; } 2 \text {. } \\
\text { Kurangnya transportasi yang ada dan } \\
\text { akses jarak ke fasilitas perawatan ke } \\
\text { fasilitas perawatan tingkat lanjut }\end{array}$ \\
\hline $\begin{array}{l}\text { Improving } \\
\text { Emergency } \\
\text { Obstetric Referral } \\
\text { Systems In Low } \\
\text { And Middle Income } \\
\text { Countries: A } \\
\text { Qualitative Study In } \\
\text { A Tertiary Health } \\
\text { Facility In Ghana }\end{array}$ & $\begin{array}{l}\text { Anita Anima Daniels } \\
\text { and Aaron Abuosi }\end{array}$ & $\begin{array}{l}\text { Rumah Sakit Pendidikan } \\
\text { Korle Bu, Ghana }\end{array}$ & $\begin{array}{l}\text { 1. Ketersediaan transportasi yang } \\
\text { digunakan untuk merujuk terbatas } \\
\text { sehingga menyebabkan keterbatasan } \\
\text { dalam merujuk pasien; } 2 \text {. } \\
\text { Ketersediaan tempat tidur yang } \\
\text { terbatas; } 3 \text {. Perlu adanya persediaan } \\
\text { peralatan medis yang memadai dan } \\
\text { persediaan medis lain yang } \\
\text { diperlukan terutama darah dan obat- } \\
\text { obatan }\end{array}$ \\
\hline $\begin{array}{l}\text { Obstetric Referrals } \\
\text { From A Rural Clinic } \\
\text { To A Community } \\
\text { Hospital In } \\
\text { Honduras }\end{array}$ & $\begin{array}{l}\text { Srirama Josyula, BS } \\
\text { (Medical Student), } \\
\text { Kathryn K. Taylor, BS } \\
\text { (Medical Student), } \\
\text { Blair M. Murphy, MD } \\
\text { (Radiation Medicine } \\
\text { Resident) }\end{array}$ & $\begin{array}{l}\text { Maternal Fetal Care } \\
\text { Clinic, Honduras, } \\
\text { Amerika Tengah }\end{array}$ & $\begin{array}{l}\text { Adanya hambatan dari infrastruktur } \\
\text { untuk transportasi yang tidak } \\
\text { memadai dari klinik yang ada di } \\
\text { pedesaan ke rumah sakit rujukan }\end{array}$ \\
\hline
\end{tabular}

\section{Kesimpulan}

Implementasi sistem rujukan berdasarkan aspek regulasi sistem rujukan layanan kesehatan yang berlaku dalam systematic review yang dilakukan oleh peneliti ditemukan hanya 2 literature. Regulasi yang menjadi acuan dalam pengimplementasian sistem rujukan yaitu PMK No. 001 tahun 2012 dimana pelaksanaan kebijakan ini belum sepenuhnya dilaksanakan oleh tenaga kesehatan dikarenakan adanya keterbatasan sosialisasi dan untuk regulasi yang berlaku di Provinsi Sulawesi Selatan menerapkan sistem regionalisasi dimana regulasi ini menjadi program unggulan dari penyelenggaraan pemerintahan. Sumber daya tenaga kesehatan dalam sistem rujukan masih menjadi faktor dilakukannya rujukan kepada pasien yang membutuhkan perawatan lebih lanjut. Hal ini membuktikan bahwa ketersediaan sumber daya tenaga kesehatan dibutuhkan untuk melakukan perawatan pasien pada layanan kesehatan serta pengetahuan tenaga kesehatan mengenai sistem rujukan diperlukan agar tidak terjadi kesalahan dalam melakukan rujukan. Keprofesionalan petugas dalam mematuhi SOP rujukan yang berlaku masih menjadi salah satu kendala penghambat dilakukannya rujukan kepada pasien dan pengetahuan masyarakat mengenai sistem rujukan yang masih minim. Sarana prasarana fasilitas layanan kesehatan dalam sistem rujukan layanan kesehatan menjadi salah satu faktor dalam melakukan rujukan terhadap pasien. Masih ada kendala dalam pengimplementasian sistem rujukan di layanan kesehatan. Kendala 
yang dimaksud masih adanya hambatan infrastruktur dan trasportasi yang tidak memadai dari layanan kesehatan yang berada di daerah pedesaan ke rumah sakit rujukan, ketidaktersediaan alat medis yang memadai, tempat tidur pasien yang tidak memadai dan ketidaktersediaannya jaringan seluler atau jaringan radio sehingga mengakibatkan terhambatnya proses rujukan pasien.

\section{Daftar Pustaka}

1. Ali F. Pelaksanaan Rujukan Rawat Jalan Tingkat Pertama Peserta Program Jaminan Kesehatan Nasional (JKN) Di Puskesmas Siko Dan Puskesmas Kalumata Kota. Jikmu [Internet]. 2015;221-37. Available from: http://ejournal.unsrat.ac.id/index.php/jikmu/article/view/7439

2. Menteri Kesehatan R. Peraturan Menteri Kesehatan Republik Indonesia Nomor 001 Tabun 2012 Tentang Sistem Rujukan Pelayanan Kesehatan Perorangan. PMK No 001 th 2012. 2012;3(September):1-47.

3. Afolaranmi TO, Hassan ZI, Filibus DI, Al-Mansur UA, Lagi LA, Kumbak FD, et al. Referral System: An Assessment of Primary Health Care Centres in Plateau State, North Central Nigeria. World J Res Rev [Internet]. 2018;(6):82. Available from: www.wjrr.org

4. Naseriasl M, Janati A, Amini A, Adham D. Referral system in rural Iran: improvement proposals. Cad Saude Publica. 2018;34(3).

5. Ramelson H, Nederlof A, Karmiy S, Neri P, Kiernan D, Krishnamurthy R, et al. Closing the loop with an enhanced referral management system. J Am Med Informatics Assoc. 2018;25(6):715-21.

6. Ratnasari D. Analisis Pelaksanaan Sistem Rujukan Berjenjang Bagi Peserta JKN di Puskesmas X Kota Surabaya Analysis of The Implementation of Tiered Referral System for Participant of National Health Security at Primary Health Center X of Surabaya. Jaki. 2017;5:145-54.

7. Pierre Ilboudo T, Chou YJ, Huang N. Compliance with referral for curative care in rural Burkina Faso. Health Policy Plan. 2012;27(3):256-64.

8. Risky S, Nofitasari A. Evaluation of the Implementation of a Referral System in the Community Health Center of Abeli, Kendari, Indonesia. Public Heal Indones. 2017;3(3):112-6.

9. Puspitaningtyas A, Indarwati, Kartikasari D. Pelaksanaan Sistem Rujukan di RSUD Banyudono. Gaster | J Ilmu Kesehat. 2014;11(2):25-36.

10. Sanjaya GY, Lazuardi L, Hasanbasri M, Kusnanto H. Using hospital claim data to develop referral decision support systems: Improving patient flow from the primary care. Procedia Comput Sci [Internet]. 2019;161:441-8. Available from: https://doi.org/10.1016/j.procs.2019.11.143

11. Triandini E, Jayanatha S, Indrawan A, Putra GW, Iswara B. Metode Systematic Literatureee Review untuk Identifikasi Platform dan Metode Pengembangan Sistem Informasi di Indonesia. Indones J Inf Syst. 2019;1(Februari 2019).

12. Alaro NL. Effective Functional Referral System Guideline And Protocols. 2016;

13. RI DJBUKKK. Pedoman Sistem Rujukan Nasional. Jakarta, Indonesia; 2012.

14. Eskandari M, Abbaszadeh A, Borhani F. Barriers of Referral System to Healthcare Provision in Rural Societies in Iran. J Caring Sci. 2013;2(3):229-36.

15. MoHCDGEC. Guideline for Regional Referral Hospital Advisory Board (RRHAB ). 2016. 1-48 p.

16. Albattal S. Management of inappropriate referrals in Wazarat health center, Riyadh, Saudi Arabia. Int J Med Sci Public Heal. 2014;3(3):269.

17. Benson AE, Benson MJ, Luke AH. Assessment of maternal referral systems used for a rural Zambian hospital: The development of setting specific protocols for the identification of complications. Afr Health Sci. 2019;19(1):1536-43.

18. Sumona, Alban; Bagbi K. Ministry of Health Referral Policy Guideline. Policy of Referring patients. 2012.

19. Ohara K, Meléndez V, Uehara N, Ohi G. Study of a patient referral system in the Republic of Honduras. Health Policy Plan. 1998;13(4):433-45.

20. Primasari KL. Analisis Sistem Rujukan Jaminan Kesehatan Nasional RSUD. Dr. Adjidarmo Kabupaten Lebak. J Adm Kebijak Kesehat. 2015;1(2):78-86.

21. AM Hafsa, A.Maidin, S.Palutturi, Stang. Regionalization referral system of the hospital national health insurance. Indian J Public Heal Res Dev [Internet]. 2020;11(3):1433-7. Available from: http://www.indianjournals.com/ijor.aspx?target=ijor:ijphrd\&type=home\%0Ahttp: / / ovidsp.ovid.c om/ovidweb.cgi? $\mathrm{T}=\mathrm{JS} \& \mathrm{PAGE}=$ reference $\& \mathrm{D}=$ emexb\&NEWS $=\mathrm{N} \& A N=2004449529$ 
22. Hermiyanty, Wandira B ayu, Nelianti F. Implementasi Rujukan Pasien JKN di Puskesmas Singgani Kecamatan Palu Timur. J Chem Inf Model. 2019;53(9):1689-99.

23. Afiyani DN, Dwimawati E, Pujiati S. Evaluasi Pelaksanaan Sistem Rujukan di Puskesmas Bogor Utara Kota Bogor Provinsi Jawa Barat Tabun 2019. Promotor. 2020;3(1):28.

24. Nestelita D, Suryoputro A, Kusumastuti W. Proses Sistem Rujukan Dalam Pelayanan Kegawatdaruratan Obstetri Dan Neonatal Di Puskesmas Sayung 2 Kabupaten Demak. Media Kesehat Masy Indones. 2019;18(4):159-63.

25. Fany PA, Sakka A, Jumakil. Implementasi Sistem Rujukan di Rumah Sakit Bhayangakara Kota Kendari Tabun 2018. J Ilm Mhs Kesehat Masy [Internet]. 2018;3(2):1-9. Available from: http://jfionline.org/index.php/jurnal/article/view/564

26. Jumbam DT, Menon G, Lama TN, Lodge W, Maongezi S, Kapologwe NA, et al. Surgical referrals in Northern Tanzania: A prospective assessment of rates, preventability, reasons and patterns. BMC Health Serv Res. 2020;20(1):1-13.

27. Daniels AA, Abuosi A. Improving emergency obstetric referral systems in low and middle income countries: $A$ qualitative study in a tertiary health facility in Ghana. BMC Health Serv Res. 2020;20(1):1-10.

28. Josyula S, Medical BS, Taylor KK, Medical BS, Murphy BM, Medicine R, et al. Obstetric referrals from a rural clinic to a community hospital in Honduras. Midwifery [Internet]. 2015;1-6. Available from: http://dx.doi.org/10.1016/j.midw.2015.07.002 